\title{
Immunochemical and Kinetic Evidence that Heparin Enhances Aprotinin Activity
}

\author{
Tadahiro SHIKIMI \\ Department of Pharmacology. Shimane Medical University. \\ zumo. Shimane 693. Japan
}

Accepted May 21, 1985

\begin{abstract}
Both immunochemical and kinetic evidence suggest that the increase in aprotinin activity in the presence of heparin is not due to an increase in the active form of aprotinin, but rather to a qualitative change in the aprotinin molecule which would lead to an increase in aprotinin activity.
\end{abstract}

Aprotinin, a basic polyvalent protease inhibitor, is present in mast cells of bovine tissue $(1,2)$ and is prescribed for patients with acute pancreatitis and shock due to acute peritonitis (3). I reported that preincubation of aprotinin and heparin, the latter a main component of mast cell granules, enhanced the inhibitory effect of aprotinin on the esterolytic activity of trypsin (4). In solution. aprotinin exists in two states, a monomer and a dimer (5-7), and the monomer form is regarded as the active form of aprotinin (810). Regarding the enhancing effect of heparin on aprotinin activity, there are at least two possibilities: (a) change in the ratio of the two states of aprotinin and (b) change in the aprotinin molecule which would lead to an increase in aprotinin activity. The present paper reports immunochemical and kinetic evidence for the enhancing effect of heparin on aprotinin activity.

A commercial sample of Trasylol, which corresponds to $1.4 \mathrm{mg}$ of crystalline aprotinin per $\mathrm{ml}$ (Bayer, A. G.), served as aprotinin. Heparin. 1,000 $\mathrm{lU} / \mathrm{ml}$, was obtained from Novo Industry, trypsin from Miles Laboratories, tosyl-L-arginine methyl ester hydrochloride (TAME) from Peptide Institute, Inc. The inhibitory effect of aprotinin on trypsin activity was measured with TAME as a substrate using the method of Simlot and Feeney (11). Immunochemical titration of aprotinin was as described (12).

The following results were obtained: 1 . As shown in Fig. 1, the equivalence points of both groups at which aprotinin activity is first detected in the supernatant were identical, but the inclination of the curve of the group preincubated with heparin $[\mathrm{H}(+)]$ was steeper than that of the group preincubated without heparin $[\mathrm{H}(-)]$. 2. Aprotinin preincubated with or without heparin caused noncompetitive inhibition of trypsin under the present experimental conditions (incubation of enzyme with inhibitor before addition of substrate and short reaction time) In the presence or absence of aprotinin, heparin did not per se have any effect on the $K_{\mathrm{In}}$ value of trypsin for TAME; however, the inhibitor constant $\left(K_{i}\right)$ for the trypsin. aprotinin complex and the trypsin.TAME. aprotinin complex was decreased in the presence of heparin (Table 1).

Gelatin, a hydrophobic protein, also enhanced the inhibitory effect of aprotinin on the esterolytic activity of trypsin (12). The enhancing effect of gelatin was due to an increase in the active form of aprotinin in solution, based on findings such as the following: in the immunochemical titration of aprotinin, gelatin treatment decreased the value of the equivalence point of aprotinin The present immunochemical result was in marked contrast with that of gelatin. In addition, using the trypsin titration technique. the amount of the active form of aprotinin which reacts with trypsin remained unchanged regardless of the preincubation with heparin (13). Heparin used in this study did not have any effect on trypsin (4) (Table 1. 


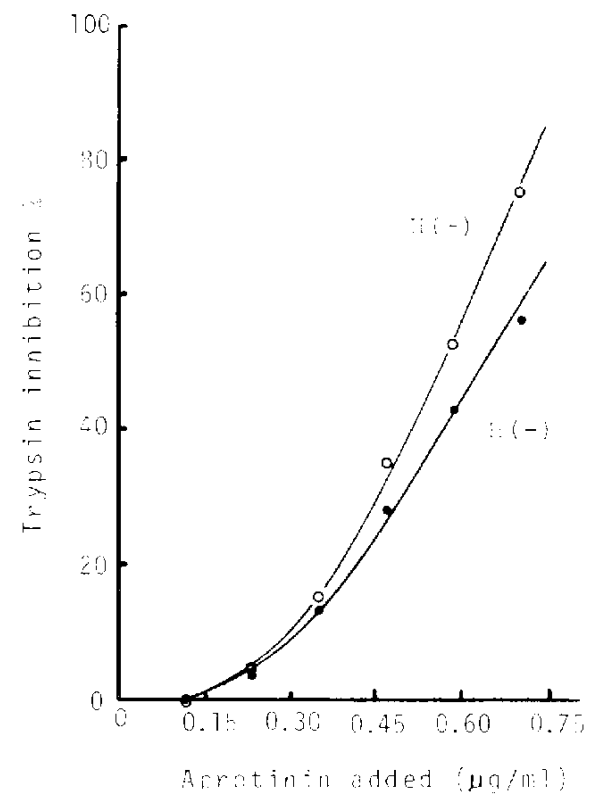

Fig. 1. Immunochemical titration of aprotinin. Various amounts of aprotinin, with or without heparin in solution, in which the ratio of aprotinin to heparin was $0.14 \mu \mathrm{g}$ to $8 \mathrm{lU}$, were prepared using a $0.9 \% \mathrm{NaCl}$ solution containing $1 \%$ benzylalcohol. a solvent used for heparin. The aprotinin solutions with heparin $[H(1)]$ or without heparin $[\mathrm{H}(-)]$ were preincubated at $37^{\circ} \mathrm{C}$ for $48 \mathrm{hr}$ and were then added to equal volumes of antiaprotinin $\mathrm{gG}$ fractions (1 $\mathrm{mg} / \mathrm{ml}$ ) in $0.9 \% \mathrm{NaCl}$ solution containing $0.07 \%$ NaN $N_{3}$. The mixture was incubated at $37^{\circ} \mathrm{C}$ for $4 \mathrm{hr}$ and was allowed to stand at $4{ }^{\circ} \mathrm{C}$ for overnight. After centrifugation at $30.000 \times \mathrm{g}$ for $20 \mathrm{~min}$, aprotinin activity in the supernatant was measured. The trypsin activity without aprotinin was taken as $100 \%$, and the trypsin inhibition \% shown on the ordinate was calculated from the trypsin activity with aprotinin in the supernatant. Each point shows the mean of triplicate assays. The equivalence points of $H(t)$ and $\mathrm{H}(-)$ were identical.

Table 1. Kinetic constants of the interaction of trypsin with aprotinin

\begin{tabular}{ccccc}
\hline & $K_{m}(M)$ & $K_{i p p}(M)$ & $K_{i}(M)$ \\
Heparin & $(-)$ & $1.0 \times 10^{-4}$ & $1.0 \times 10^{4}$ & $6.0 \times 10^{-3}$ \\
& $(+)$ & $1.0 \times 10^{-4}$ & $1.0 \times 10^{-4}$ & $2.5 \times 10^{-8}$ \\
\hline
\end{tabular}

Aprotinin $(0.56 \mu \mathrm{g} / \mathrm{ml})$ was preincubated with or without heparin $(32 \mathrm{lU} / \mathrm{ml})$ at $37^{\circ} \mathrm{C}$ for 48 hr. The preincubation mixture was incubated with trypsin $(5 \mu \mathrm{g} / \mathrm{ml})$ at $37^{\circ} \mathrm{C}$ for $5 \mathrm{~min}$, and then various amounts of substrate (TAME) were added. The enzymatic activity of trypsin was measured by the method of Simlot and Feeney. The kinetic ccnstants of the interaction of trypsin with aprotinin were obtained from Lineweaver-Burk piots and Hofstee plots of the data. $\mathrm{K}_{\mathrm{m}}$ : Michaelis constant of trypsin for TAME in the absence of aprotinin. Kapp: Apparent Michaelis constant of trypsin for TAME in the presence of aprotinin. $K_{i}$ : Inhibitor constant for trypsin-aprotinin complex and trypsin.TAME.aprotinin complex obtained in the noncompetitive inhibition.

$K_{\pi}$ and $\left.K_{a p p}\right)$. While it easily binds to aprotinin in vitro (14). On the other hand, the change in $K_{i}$ value for the trypsin-aprotinin complex and the trypsin.TAMEaprotinin complex was observed in the presence of heparin. These findings also suggest that the enhancing effect of heparin is not due to an increase in the active form of aprotinin, but rather to some qualitative change in the aprotinin molecule which would lead to an increase in aprotinin activity. Details on the change in the aprotinin molecule induced by heparin remain to be determined.

\section{References}

1 Fritz, H., Kruck, J., Rüsse, 1. and Liebich, H.G.:
Immunofluorescence studies indicate that the basic trypsin-kallikrein-inhibitor of bovine organs (Trasylol) originates from mast cells. Hoppe Seylers Z. Physiol. Chem. 360, 437-444 (1979)

2 Shikimi, T. and Kobayashi, T.: Production of antibody to aprotinin and location of this compound in bovine tissue. J. Pharmacobiodyn. 3, 400-406 (1980)

3 Vogel, R. and Zickgraf-Rüdel, G.: Evaluation of the role of kinins in experimental, pathological, and clinical conditions: the therapeutic use of kallikrein inhibitor. In Bradykinin, Kallidin and Kallikrein, Edited by Erdös, E.G., p. 550-578. Springer-Verlag. Berlin (1970)

4 Shikimi, T.: Enhancing effect of heparin on aprotinin activity. Experientia 37, 1179-1180 (1981) 
5 Anderer, F.A. and Hörnle, S.: 1. Molekulargewicht, Endgruppenanalyse und Aminosäure-Zusammensetung. Z. Naturforsch. 20b, 457-462 (1965)

6 Burger, K., Zay, I., Gaizer, F. and Noszál, B.: Protonation and dimerization equilibria of the basic trypsin inhibitor (Kunitz base). Inorg. Chım. Acta 34, L239-L241 (1979)

7 Wills, P.R. and Georgalis, Y.: Concentration dependence of the diffusion coefficient of a dimerizing protein: Bovine pancreatic trypsin inhibitor. J. Phys. Chem. 85, 3978-3984 (1981)

8 Kunitz, M. and Northrop, J.H.: Isolation from beef pancreas of crystalline trypsinogen, trypsin, a trypsin inhibitor. and an inhibitor-trypsin compound. J. Gen. Physiol. 19, 991-1007 (1936)

9 Fritz, H., Trautschold, I, and Werle, E.: Bestimmung der Moleku!argewichte von neuen Trypsin-Inhibitoren mit Hilfe der Sephadex-
Gelfiltration. Hoppe Seylers Z. Physiol. Chem. 342, 253-263 (1965)

10 Scholtan, W: Bestimmung der Wechselwirkung zwischen Trypsin und dem Kallikrein-Inaktivator mittels der Ultrazentrifuge. Hoppe Seylers Z. Physial. Chem. 348, 1193-1196 (1967)

11 Simlot, M.M. and Feeney, R.E.: Relative reactivities of chemically modified turkey ovomucoid. Arch. Biochem. Biophys. 113, 6471 (1966)

12 Shikimi, T., Tanabe, Y. and Hattori, K.: The enhancing effect of gelatin on aprotinin activity. Japan. J. Pharmacol. 36, 197-203 (1984)

13 Shikimi, T.: Effects of dextran sulfate on aprotinin activity. Japan. J. Pharmacol. 39 (1985) (in press)

14 Stoddart, R.W. and Kiernan, J.A: Aprotinin, a carbohydrate-binding protein. Histochemie 34, 275-280 (1973) 